\title{
Sustainable development as a trigger for new architectural and spatial solutions
}

\author{
Egor Belash ${ }^{1, *}$ \\ ${ }^{1}$ Moscow Architectural Institute (State Academy), 107031 Rozhdestvenka st. 11/4, building 1.p. 4, \\ Moscow, Russia
}

\begin{abstract}
Architecture acquires its relevance at the moment when the architect shifts his attention from specific architectural issues about space, composition, functional program, etc. to something that goes beyond professional issues. He begins to think about architecture from the perspective of other disciplines, for example, from the perspective of sustainable development and ecology. These changes give rise to new spatial solutions that could not have arisen if the architect had not changed his way of thinking. Ecology is already used by some architects not only as a way to make the building more efficient, but it allows to find a new basis of thinking about architecture, where the shape and space of the building are subject to energy efficiency, environmental friendliness and adaptability. The goal of the article is to identify the methods of generating new architectural and spatial structures in the buildings of modern architectural firms that arose because of changing in the terminological apparatus of thinking about architecture based on an ecological approach. Several illustrative projects are considered in the work and two types of spatial construction, conditionally called natural and artificial, are revealed on their example. These two methods of shaping stem from the ecological approach and enter into an interesting dialogue, which is expressed in new non-standard solutions for shape of a building.
\end{abstract}

\section{Introduction}

With the advent of environmental science as one of the dominant trends in the development of modern culture, architects have found a new conceptual and ideological basis that affects the spatial structure of the projects they create. This paper analyzes the relationships between the shape of the building and the sustainable development. Green building issues are described in the works of A. Gore, W.R. Blackburn, D. Gottfried, M. Gernot, F. Jason, J. Yudelson, H. Komiyama, S. Kraines, N. A. Saprykina, B. Norton [1-10]. Nevertheless, it has not yet been considered how a new way of thinking about a project from an ecological perspective directly affects the process of architectural work, provoking architects to develop new spatial solutions resulting from interdisciplinary synthesis.

* Corresponding author: e.belash@markhi.ru 
The purpose of the study is to identify the methods of generating new architectural and spatial constructions of some modern architectural firms that arose as a result of a changing in the terminological apparatus of thinking based on an ecological approach.

A preliminary analysis of the project material [18-21] made it possible to formulate a hypothesis that the trend of sustainable development has changed the semantic content of the projects of many architectural firms, which in turn has resulted in specific methods of geometric construction of buildings and in new scenarios of their spatial development.

The tasks of the work are to analyze several iconic contemporary projects and to reveal the relationship with the ecological way of thinking in them. Then it is planned to make a number of generalizations revealing the nature of this relationship, as well as to classify the methods of morphogenesis that are used by architectural firms.

\section{Materials and methods}

The study considers the projects and buildings of modern architectural firms, in which the issues of green building formed the basis of the architectural concept and provoked the emergence of new spatial structures.

To analyse the projects we use structural and semiotic methods based on the works of C. Pierce, R. Bart, M. Foucault, J. Derrida, J. Baudrillard, A.M. Pyatigorsky, Yu.M. Lotman [11-16]. The structural method, as applied to the subject of research, is to analyze the relationships between environmental design and the highly professional field of problems, as well as emerging of new elements at the junction of these scopes.

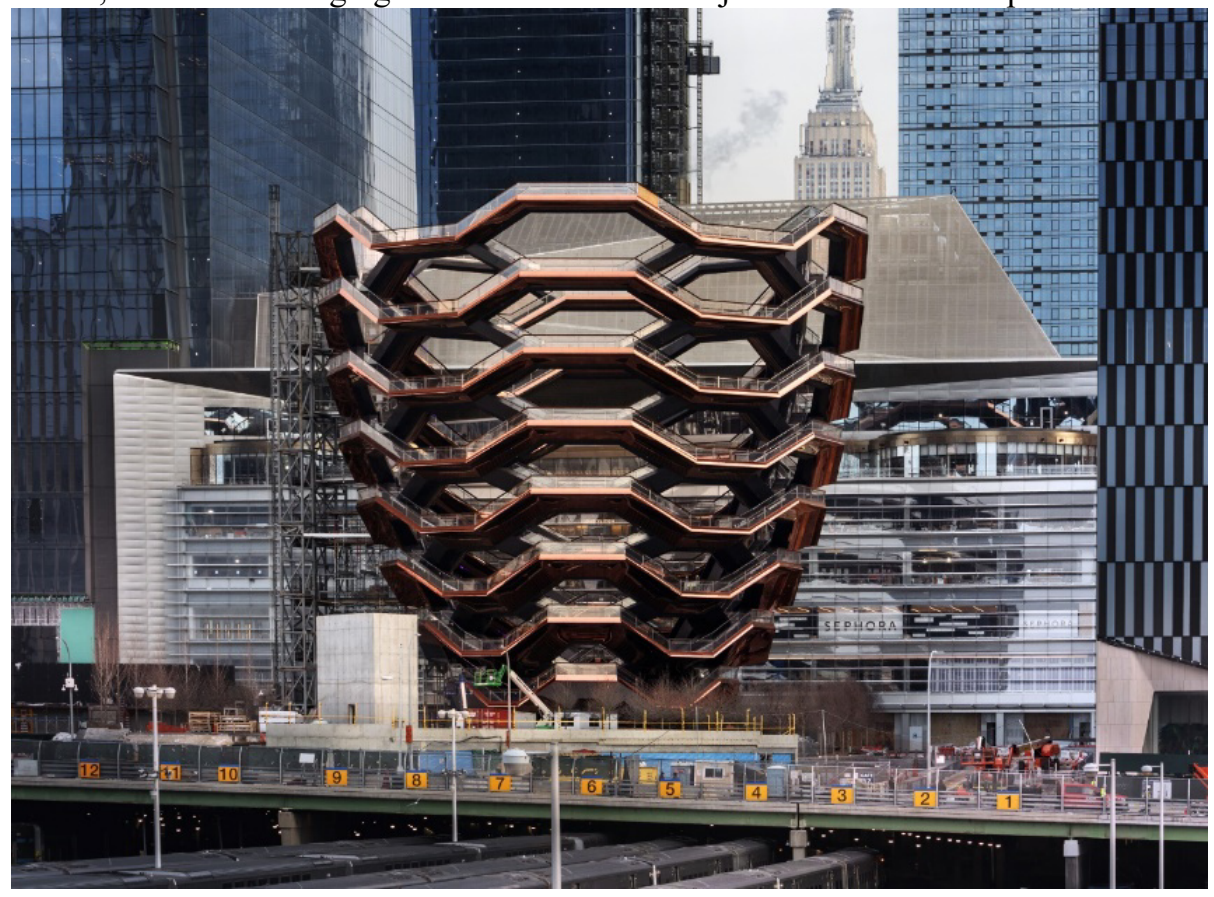

Fig.1. Vessel Public Landmark by Heatherwick Studio, source: http://www.heatherwick.com/project/vessel.

In the Vessel project by Heatherwick Studio (Fig. 1) environmental thinking led architects towards creating an object that would not fulfill commercial functions. They create a staircase structure expanding to the top. In the process of its development, people gain new experience in contemplating a city that is not related to consumption. The lower 
planes of the building are made of reflective metal. Due to the complex pattern of reflections and highlights, the repeating geometric pattern of the design does not look monotonous. Architects think of the structure as a walking zone, multiplying the potential of the site. Stairways of a pedestrian path form a hexagonal structure. The porous geometry of the building allows to increase many time over the number of pedestrian zones. The resulting ornament of the building differs greatly from the geometry of the environment, entering into a dialogue with the forms of Manhattan skyscrapers. It has strong visual differences that should attract the attention of passers-by and provoke them to walk along a pedestrian path.

The symbolism of the building refers to the sacred stepped wells of India. By placing such a form in the context of New York, architects thereby tried to recreate the spatial scenario of a meditative walk with a rhythmic repetition of the staircases descending to the park. The geometric pattern of the pedestrian path brings a metronomy to the walk and allows the person to switch to contemplating the surrounding urban landscape. Such a scenario of moving in space in terms of its philosophical characteristics has the opposite development vector in relation to the ideology of a consumer society. To sum it up, architects saturate New York city sights with new meanings, which are expressed in the specific geometric characteristics of the object. They contrast with the environment and diversify into the semantic field of the urban landscape. The non-standard walking route directly affects the visitor's perception by changing the familiar ways of space exploration and behavioral stereotypes.

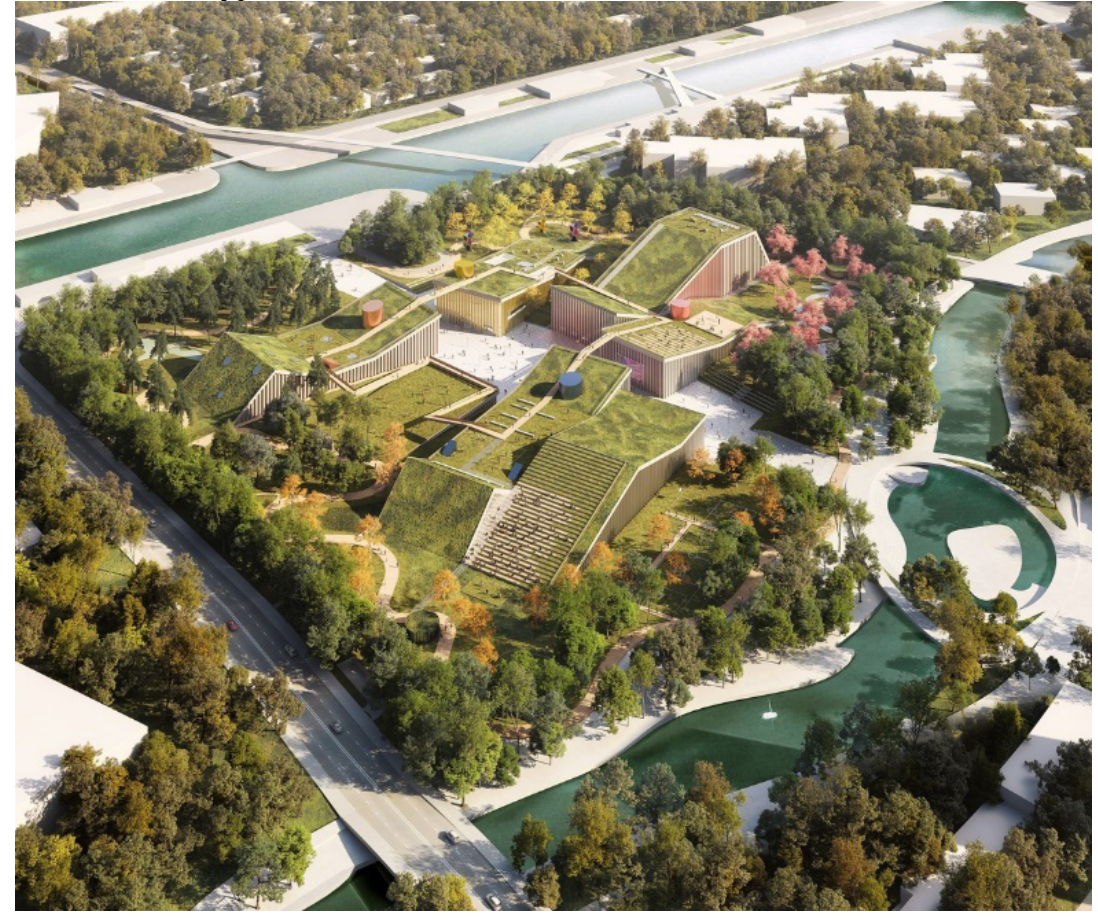

Fig. 2. Zhangjiang Future Park by MVRDV, source: https://www.mvrdv.nl/projects/295/zhangjiangfuture-park.

In the Zhangjiang Future Park project in China by MVRDV (Fig. 2) the cultural center building is reinterpreted as a landscape integrated into the park. Morphogenesis is the differentiation of volume into tape forms, which smoothly pass into the ground, thereby opening access to the roof. As a result, the pedestrian structure of the building becomes multi-level. The building saves territorial resources due to the fact that the site area is 
duplicated at an additional pedestrian level, which duplicates the main parameters of the park area: landscaping, sports fields, public areas, terraces, etc. At the same time, the relief of the tape volumes allows to enrich the plain area and let people contemplate the surroundings from the height of the second pedestrian level. In the middle of the building, the tape volumes are interrupted at the highest point, forming a gap in the continuous form of the landscape. By means of this geometrical operation, architects add a public area in the center, from which people can enter the pavilions. As a result, the architects think of the building not as an discrete object, but as part of the landscape. They use appropriate terminology and images for this (hill, landscape, gap, etc.)

Such an approach allows them to change the spatial structure of a typical cultural center, spreading it over the site and fitting it into the surrounding park area. The building acts as a hybrid of scenarios of the rich social life of the city center and a quiet park area. Layering of scenarios on top of each other is carried out by crossing the pedestrian routes adjacent to the site. Dense pedestrian traffic runs perpendicular to the tape volumes. The shape of the building reacts to it with gaps in a continuous landscape. Moreover, the width of the gap varies depending on the height of the tape volume. The flux density intentionally thickens in the most functionally loaded places. Using this technique, architects do not smooth out, but, on the contrary, exaggerate the social processes taking place in the building.

They also carefully directed scenarios of visual interaction between visitors. The path passing through the roof either approaches the very edge of the tape volume, either leaves deep into the landscape, or crosses a gap in the landscape. As a result there is a dynamic visual communication between pedestrian levels. The dense pedestrian flow at the lower level is interpreted as a river through which architects throw bridges. The processes of intense urban life in the context of the project become a natural element that erodes the rock.

The outer walls of the tape volumes are made in the form of continuous glazing dissected by the vertical rhythm of closely spaced imposts. Such a solution reveals the thickness of the roof overlap, which becomes a thin shell of greenery, covering the pavilions. Public space comes under this shell. The gorge exterior goes into the interior of the pavilions, the monotonous facade solution of which emphasizes the unnatural character of the processes taking place in them. The interaction between the levels is enhanced by vertical communications that go out onto the roof surface with colored cylinders. Such bright accents on the background of the green landscape accentuate the invasion of urban flows in the park landscape. 


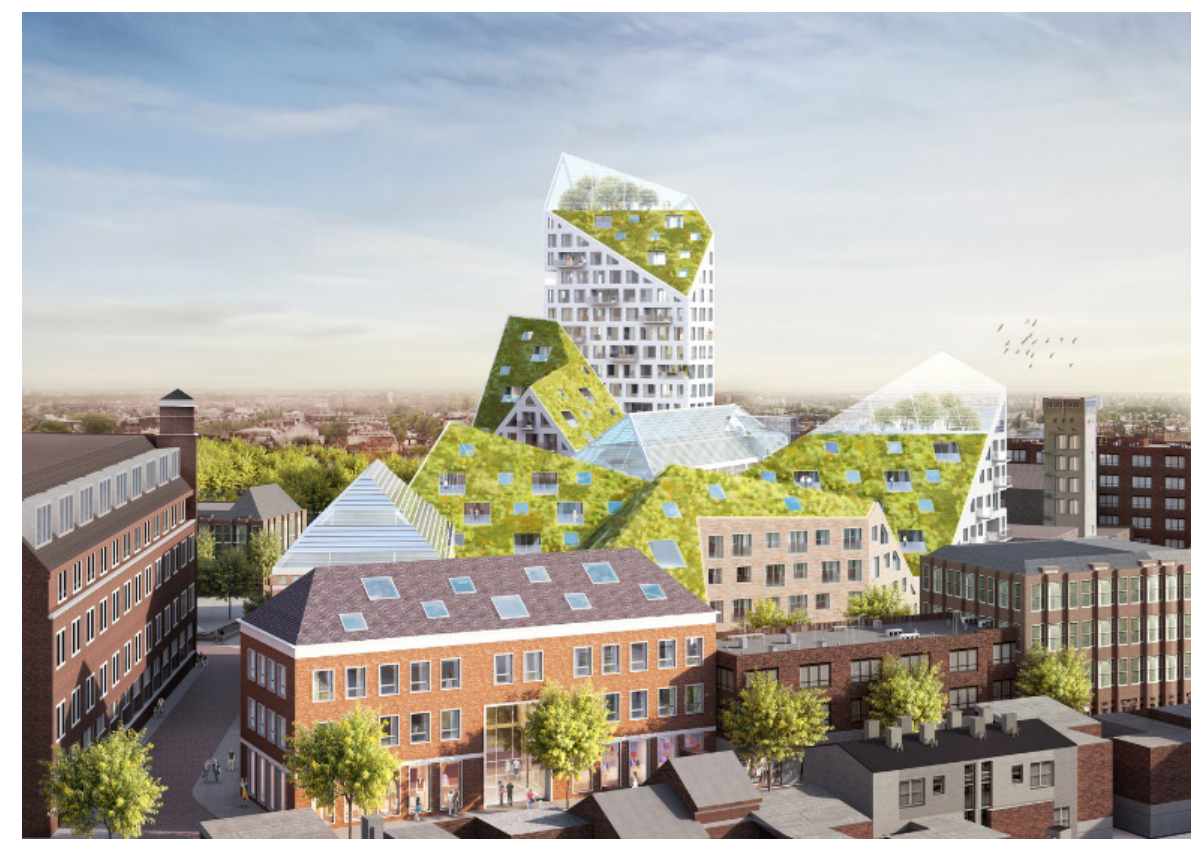

Fig.3. Housing Complex in Eindhoven by MVRDV, source: https://www.mvrdv.nl/projects/290/nieuw-bergen
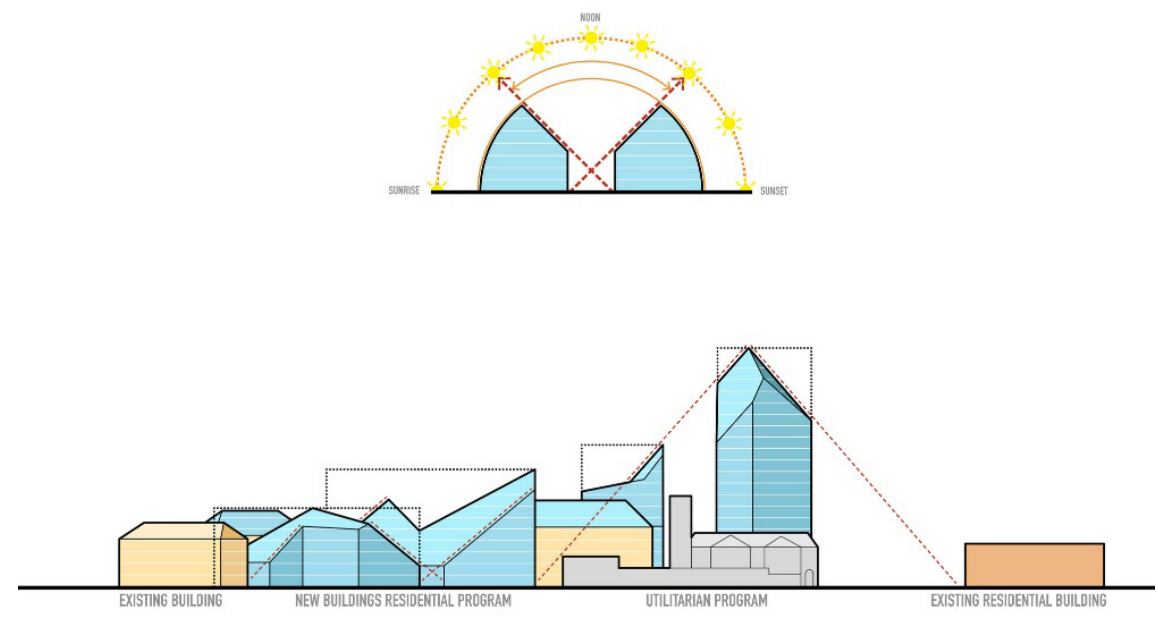

Fig. 4. Housing Complex in Eindhoven by MVRDV (Solar diagram), source: https://www.mvrdv.nl/projects/290/nieuw-bergen

A similar approach can be found in the Housing Complex in Eindhoven by MVRDV (Fig. 3). But in this case architects come to imitate the landscape through the desire to improve the visual ecology of the complex. They cut the volume of buildings depending on the lighting requirements on the site. On some roofs there are greenhouses that expand the 
public spaces of the site. The angle of the roof is also dictated by the optimal placement of solar panels. (Fig. 4)

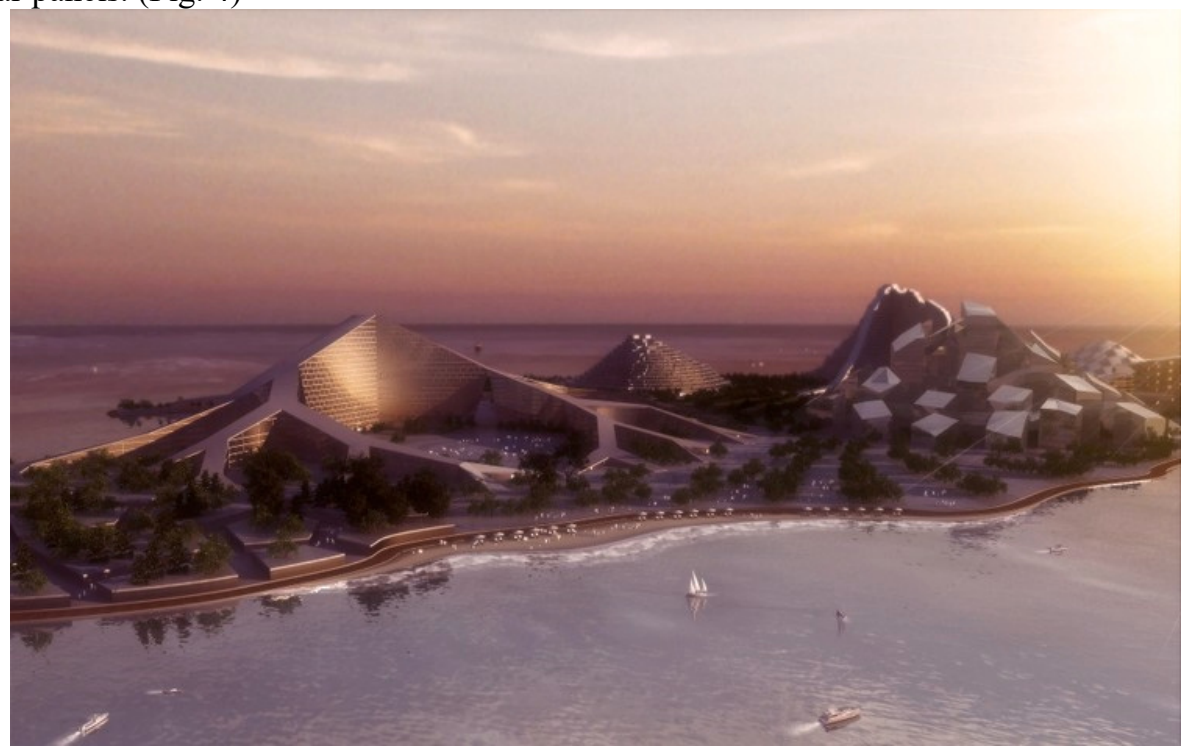

Fig. 5. Zira Island by BIG Architects, source: https://big.dk/\#projects-zir

In the Zira Island project in Azerbaijan by BIG (Fig. 5) architects directly borrow the silhouettes of local mountain peaks and translate them into the shape of buildings. The desire to create an ecological complex makes them radically change the usual methods of spatial solution of residential buildings. The project is filled with solar panels, windmills, a water recovery system, desalination plants, which allows to maximize the energy efficiency and economy of the complex. Architects claim that in this way they create a holistic ecosystem, where the forms of buildings and their internal content are combined into a single system. Architects also use wind flow simulations to optimally organize pedestrian paths on the site. As a result, the natural forces, cultural features of the place and technological devices are synthesized into a holistic idea, where each element works for a common system. Ecological thinking serves as a trigger for new spatial constructions.

The ecological approach to understanding architectural space also leads to new types of spatial development of territories. In particular, such areas of architecture as construction on water are actively developing. This direction is associated with the saving of land resources due to the development of habitats that were previously unsuitable for life. Unusual construction conditions are a capacitor of unexpected architectural and spatial solutions. A new typology of water structures appears, depending on their location relative to the water level and layout options for floating foundations. [17]

\section{Results and Discussion}

As a result new architectural methods and techniques were identified, the specificity of which is in their close relationship with the issues of green construction. A number of projects were analized and the following types of relationships between the environmental approach and architectural shaping were established:

- Architectural project is considered as a natural landscape. Architects use appropriate terminology and imagery; 
- Urban processes are considered as a natural element that interacts with the geometry of the building and changes it;

- The spatial structure of the building can repeat behavioral scenarios from other cultures, that change habitual ways of spatial accommodation;

- At the same time, architects cannot go entirely into this metaphorical way of thincking, as the ecological approach requires rational and scientific approaches;

- These metaphorical and rational ways of thinking contradict each other. Architects begin to rethink the shape of the building in an attempt to resolve this contradiction.

The characteristic principles of shaping, which can be observed in many modern projects, were also highlighted:

- The forms of projects are differentiated according to the semantics of natural and artificial, which stem from the desire to comprehend the building as a natural object while maintaining the rationality and consistency of the overall plan;

- "Artificial" forms have orthogonal geometry and contain a large number of repeating elements;

- "Natural" forms are represented by non-linear geometric solutions and non-standard elements of different shapes and sizes.

- These two types of geometry enter into complex interaction with each other and lead to non-standard geometric solutions that manifest themselves differently in specific projects.

\section{Conclusion}

In conclusion, environmental thinking stimulates the emergence of new approaches to form finding. Architects strive to figuratively emphasize the environmental friendliness of the project and actively use biomorphic forms, which nevertheless differ from deconstructivist projects. The requirements of profitability and efficiency do not allow architects to use irrational spatial solutions, so the desire to make them as economical and logical as possible is added to their desire to make complex natural forms. This contradiction gives rise to an interesting nuance in shaping. Simple geometric solutions interact with complex biomorphic geometry. A contradiction arises between several types of geometrical construction. These two methods of shaping stem from the ecological approach and enter into an interesting dialogue, which is expressed in new non-standard solutions for the shape of the building. The following works should expand the scope of projects and establish the structure of this dialogue.

The reported study was funded by RFBR, project number 19-312-90027.

\section{References}

1. A. Gore, An Inconvenient Truth (Rodale Press, Emmaus, 2006)

2. W.R. Blackburn, The Sustainability Handbook (Earthscan, London, 2007)

3. D. Gottfried, Greed to Green (WorldBuild Publishing, Berkeley, 2004)

4. M. Gernot, Building with Earth. Design and Technology of a Sustainable Architecture (Publishers for Architecture, Birkhäuser, 2006)

5. J. Yudelson, Developing Green: Strategies for Success (National Association of Industrial and Office Properties, Herndon, 2006)

6. F. Jason, The Philosophy of Sustainable Design; The Future of Architecture (Ecotone Publishing, 2004) 
7. H. Komiyama, S. Kraines, Vision 2050: Roadmap for a Sustainable Earth (Springer, Berlin, 2008)

8. N. A. Saprykina, Formirovanie eko-ustojchivoj sredy obitaniya budushego: Teoriya, Praktika, Perspektivy (Palmarium Academic Publishing, Saarbrücken, 2017)

9. B. Norton, Sustainability. A Philosophy of Adaptive Ecosystem Management (The University of Chicago Press, Chicago, 2005)

10. J. Yudelson, The green building revolution (Island Press, Washington, 2013)

11. R. Bart, Mifologii (Akademicheskij proekt, Moscow, 2010)

12. J. Baudrillard, Simmulyakry i simulyaciy (Postum, Moscow, 2015)

13. J. Derrida, Posicii (Akademichesky proekt, Moscow, 2007)

14. Yu.M. Lotman, Vnutri myslyashhix mirov (Azbuka-Attikus, Saint Petersburg, 2015)

15. A.M. Pyatigorskij, Myshlenie i nablyudenie. Chetyre lekcii po observacionnoj filosofii (Azbuka, Moscow, 2016)

16. M. Foucault, Arxeologiya znaniya (Gumanitarnaya akademiya, Moscow, 2012)

17. S.A. Kizilova, E3S Web of Conf., Form and functional features of modular floating structures, 91 (2019)

18. V. Patteeuw, Reading MVRDV (NAi Publishers, Rotterdam, 2003)

19. B. Ingels, Yes is More. An archicomic on Architectural Evolution (Taschen, Koln, 2009)

20. B. Ingels, Hot To Cold: An Odyssey of Architectural Adaptation (Taschen, Köln, 2015)

21. T. Heatherwick, Thomas Heatherwick: Making (The Monacelli Press, 2015) 